\title{
Progress and attainment during primary school: the roles of literacy, numeracy and self-regulation
}

\author{
Kathryn Duckworth and Ingrid Schoon \\ Institute of Education, University of London \\ K.Duckworth@ioe.ac.uk
}

(Received May 2010 Revised June 2010)

\section{Abstract}

Academic achievement is a cumulative process marked by both continuity and change over time. Research increasingly documents the critical importance of not only language and mathematical competency for academic success, but also the centrality of wider skills that enable pupils to regulate their own learning behaviours. This paper examines the balance that exists between change and stability in different domains of children's academic achievement during middle childhood and the relative importance of achievement, attention and related features of self-regulation skills for subsequent achievement. Using data from the Avon Longitudinal Study of Parents and Children, the analysis attempts to move beyond a narrow view of educational success and seeks to inform the understanding of how changes in children's developing capabilities predict educational success at the end of primary school in English and mathematics. The results demonstrate a clear pattern of continuity in attainment but also evidence of mobility both up and down the achievement distributions. In line with an increasing body of literature, the findings also show evidence of a remarkable persistence in skills related to attention as important predictors of later achievement.

\section{Introduction}

Continuity in cognitive attainments is now a well established phenomenon in developmental research (Kowleski-Jones and Duncan 1999; McCall, Applebaum and Hogarty 1973; Wilson 1983). A wealth of data shows that children's achievement test scores are strongly related to their prior cognitive functioning and attainment of basic skills in mathematics and literacy. Many studies also highlight the predictive power of achievement at the end of primary school, around age 11, for a broad range of successful outcomes in adulthood (Feinstein and Bynner 2004). However, although academic attainment is largely stable throughout childhood, children do demonstrate both shifts and fluctuations in the trajectories in the development of these skills, particularly during the early and middle schooling childhood period (Huston and Ripke 2006; Pungello et al 1996).

Cumulative evidence has also highlighted the role of broader skills and capabilities, often called "noncognitive skills" (Heckman and Rubenstein 2001), for educational success, placing a particular emphasis on the importance of attentional skills and related features of self-regulation (Duncan et al., 2007; Breslau et al., 2009). Moreover, developments in both academic and non-academic capabilities are closely intertwined with efforts to promote children's early social and emotional learning carrying positive gains to both concurrent and future attainment (Hallam, Rhamie \& Shaw, 2006; Rimm-Kaufman et al., 2007; 
Zins et al., 2004). Yet in the current era of assessment practices and standards-based accountability, schools may feel pressured to de-emphasise the development of these broader capabilities and in doing so limit the opportunity for every child to "develop at the best pace, and [ensure that] no child gets left behind" (DfES, 2006, p.1).

This paper explores the balance that exists between change and stability in different domains of children's academic achievement during primary school. The analysis seeks to inform the understanding of how changes in achievement and pupils' capabilities to regulate their own learning over the Key Stage 1 (KS1) period', predict subsequent educational success at the end of primary school in English and mathematics Key Stage 2 (KS2) tests (the National Curriculum assessments at the end of primary school). Finally, following on from the more holistic approaches to the development of children's cognitive capacities outlined in Schoon et al 2010 (thisissue), we investigate links between measures of achievement, attention and related features of selfregulatory and motivational skills. Using longitudinal data from a cohort of children born in the early 1990s, this paper considers how the different foundation stones of literacy and numeracy, attention and other features of self-regulation, such as locus of control and scholastic competence, operate to support progress and attainment once children are in formal schooling. The methodology used attempts to isolate the relative contributions of skills and capabilities developed during the early school years for later academic success, by controlling for earlier development as well as for an extensive set of prior child and family influences associated with children's achievement.

\section{Development in middle childhood}

Middle childhood roughly spans the period from 5 to 12 years of age and is marked by considerable developmental changes in many domains (Collins 1984). Consequently it has been distinguished from early childhood and adolescence along a number of dimensions, yet has received comparatively little attention relative to other developmental periods, such as infancy, early-childhood and adolescence (Huston and Ripke 2006). Moreover, the period between 5 and 7 years of age forms the first years of schooling for almost every society that provides formal education, suggesting some universal recognition that the abilities needed for such schooling emerge during this age period.

Throughout middle childhood, children become more adept at acquiring new information, consolidating, extending and integrating previously acquired knowledge, and using this information in subsequent reasoning and action. Evidence here suggests that during this period of development, children 'learn to learn', adapting previous strategies to develop new cognitive skills that enable them to think more flexibly and subtly than during the preschool years (Hiebert and Wearne 1996; Leppänen, Niemi, Aunola and Nurmi 2006; Scarborough 2001; Storch and Whitehurst 2002). As these skills become more automatic, attentional resources can be devoted to learning more complex tasks and making learning more efficient. Such evidence has contributed to the move away from discrete, qualitative stages in development, towards the recognition that individual development is a continual process, where children steadily become better and more efficient information processors as skills advance and the brain develops a greater capacity for more complicated procedures (Keating 2004; Siegler and Alibali 2004).

Given that the learning trajectories children embark on during primary school are marked by both stability and change, practitioners and policy makers need to have a clear understanding of this balance, to best support progression in learning for all children. There is therefore a need to address questions that focus on the extent to which, and in what ways, fundamental skills implicated in educational success are fixed or become crystallised, before children make the important transition to secondary school. By understanding the complex patterns of stability and change in attainment during primary school, we will be better placed to address disparities of underachievement and ensure that every child is able to achieve their full potential.

\section{Beyond a narrow view of academic achievement}

Success in school, while clearly dependent on general intelligence, foundational skills in literacy and numeracy and other cognitive processes such as memory, is also a product of broader self-regulatory 
and socio-emotional skills and individual adjustment (Duncan et al 2007; Heckman, Stixrud and Urzua 2006). Attention and related self-regulatory features of the child, such as concentration and persistence versus impatience and impulsivity, are expected to increase, or decrease, the capacity that children have for engagement in the classroom, as well as their level of sustained participation in academic activities. While less common than research on development of cognitive skills, studies investigating the associations between children's attention-related classroom behaviour and school performance, consistently suggest that the ability to control and sustain attention predicts achievement during pre-school and school years (Alexander, Entwisle and Dauber 1993; Raver, Smith-Donald, Hayes and Jones 2005). Moreover, these authors suggest that children who are engaged, interested and pay attention, not only spend more time on task, but also invest in greater quality time in this respect.

Recent research documenting the particular importance of attentional skills for subsequent academic achievement shows that, while attention problems are frequently found in conjunction with other behavioural difficulties, they are conceptually distinct from other problem behaviours, and relate to achievement outcomes in unique ways. For example, Duncan and colleagues (2007) found that the association of disruptive behaviours and emotional problems had no bearing on school performance once attention was taken into account (see also Barriga et al 2002; Breslau et al 2009). This association is true, independent of prior levels of cognitive attainment (see also McClelland, Morrison and Holmes, 2000; Yen, Konold and McDermott, 2004) and after taking into account changes in attentional skills over time (Breslau et al 2010), further indicating that children with greater and more adaptive self-regulatory skills are more likely to succeed academically. Moreover, while the contribution of learning-related behaviours is relatively small in comparison to academic ability, authors here highlight that skills such as attention, persistence, perceived control, motivation and confidence are more easily amenable through intervention (Blackwell, Trzesniewski and Dweck 2007; Diamond, Barnett, Thomas and Munroe 2007; RimmKaufmann et al 2007).

\section{Aims and Hypotheses}

The aims of this investigation were twofold: (1) to explore the degree of stability versus malleability in the development of literacy and numeracy across the Key Stage assessments; and (2) to examine the relative importance of changes in developing skills and capabilities for achievement at the end of primary school. By examining how children progress over the KS2 period using a broad set of developing capabilities, the analyses aim to unpack some of the individual differences, progression disparities and attainment gaps that can get averaged out in nationally descriptive, target-focussed-only data.

\section{Method}

\section{Data}

The study is based on data collected for the Avon Longitudinal Study of Parents and Children (ALSPAC), an ongoing population-based study designed to investigate the effects of environmental, genetic and other influences on the health and development of children (Golding, Pembrey, Jones and the ALSPAC study team, 2001). To be eligible for the study, mothers had to be resident in the former Avon Health Authority area while pregnant, with an expected date of delivery between 1st April 1991 and 31st December 1992. iii More than $80 \%$ of the known births from the geographically defined catchment area were included, resulting in a total cohort of 14,062 live births.

These data are unique amongst large sample, longitudinal birth cohort studies in the UK, in surveying children year on year, plus each child's mother and her partner(s) at short, regular intervals, prenatally and later on. The study contains a wealth of data on family background, family process, the cognitive, social and behavioural development of children, and key features of the school environment. In addition, school-level data including Local Education Authority (LEA) entry assessment scores were obtained, and administrative data from the National Pupil Database (NPD) have been merged with the ALSPAC data, providing records of individual achievement in the National Curriculum Key Stage 1 and 2 assessments. These data cover all 
relevant state schools in the four LEAs that cover this area now; Bristol, South Gloucestershire, North Somerset, and Bath and North East Somerset.

\section{Measures}

\section{Outcome measures}

Academic achievement is assessed in Year 6, the final year of primary school, when children are aged between 10 and 11 years old, in terms of Key Stage scores in English and mathematics. The English assessment is marked out of 100 and consists of three tests: a reading test, a writing test and a spelling test. Marks are also awarded for handwriting. The mathematics test is marked out of 100 and consists of three separate tests: a calculator paper, a noncalculator paper and a mental arithmetic test. Additional marks for both English and mathematics can be gained through pupils sitting extension papers, with marks added onto their individual result to minimise any possible ceiling effects. At Key Stage 2, the national target is for $85 \%$ of 11 year olds to achieve Level 4 or above in English and mathematics. In 2002/2003, the year most ALSPAC children sat their KS2 assessments, this figure was 75\% for English and 73\% for mathematics (DfES 2003).

The raw information available regarding actual marks is used to calculate 'exact' attainment levels, measured on the same scale as the National Curriculum final levels awarded. To illustrate this, consider the following example: pupils who were awarded Level 3 in English at KS2 would have achieved a mark between 24 and 43 on the English paper. The method used in this paper assigns an attainment level of 3.00 to a child who scored 24 , for instance, and 3.950 to a child who scored 42; a pupil whose score was in the middle of the two thresholds (i.e. 34) is assigned a level of 3.5 (for further details of this interpolation formula see Levačić, Jenkins, Vignoles et al 2005). The advantage of this approach is that in producing a more continuous measure of attainment, we are better able to rank pupils in terms of their achievement at each Key Stage. Further, it controls for the year the pupil took their KS2 assessments and the variations in cut scores each year. In the regression analysis it also enables an approximation of the amount of 'monthly progress' made. $^{\text {iv }}$

\section{Key Independent Variables: Key Stage 1 assessments}

The KS1 assessments consist of standardised tests in reading, writing, spelling and mathematics, administered in Year 2 of primary school when pupils are 6-7 years old. For this sample, the tests would have been conducted in the period 1997/98 to $1999 / 2000$. The metric of these assessments is only available in terms of discrete Key Stage levels and consists of Levels 1, 2, 3 and 4+, with Level 4+ being the highest ${ }^{v}$ and grades $A$ (high), B and C (low) separating out Level 2. In addition, code W ('working towards Level 1') means the child was assessed but did not achieve Level 1. Children who were absent or disapplied $^{\mathrm{vi}}$ from the KS1 tests are excluded from all analyses. The target level for all children at Key Stage 1 is Level 2, specifically Level $2 B$.

Despite the discrete level categories, the relationship between KS1 assessments and KS2 attainment is remarkably linear (results not reported). As such, in the analysis presented below, the KS1 measures are treated as continuous. For simplicity, we use an overall measure of literacy taken as the first factor solution of the reading, writing and spelling assessments. Sensitivity checks on these data revealed remarkably linear relations within each assessment and in their predictive associations with the KS2 assessments. Therefore the use of an overall literacy score is not considered problematic. KS1 assessments were standardised with mean $=0$, standard deviation $=1$.

\section{Key Independent Variables: Clinic assessments at age 8}

Inattention. Three tasks, taken from the TEACh (Tests of Everyday Attention for Children) adapted from the adult version by Robertson 1996), were given to children during the clinic assessment at age 8 , reflecting three attentional domains: selective attention; the ability to divide attention between two tasks, and attentional control (Posner and Petersen 1990). These three latent constructs of underlying cognitive attention processes appear stable across the life course and have been shown to better capture the non-unitary nature of attention (Chan, Lai and Robertson 2006; Manly et al 2001). The overall 
measure of attention used was taken as the first factor of these three scores.

Locus of control. Locus of control assesses selfperceived control in individuals' lives. People who believe that an outcome is largely contingent on their own actions are seen as having a more internal locus of control, while those who feel that their lives are determined more by luck, fate, chance and other people, are considered to have an external locus of control (Deci and Ryan 1987). Measures of internality and externality have been shown to be associated with a number of different factors, including academic achievement, psychological well-being and beliefs (Lefcourt 1982). The measure used here was a shortened, 12-item version of the Nowicki-Strickland Internal-External scale (NSIE scales, Nowicki and Duke 1974) for pre-school and primary children, and included questions such as "Is doing well in your class-work just a matter of 'luck' for you?", "Do you think that preparing for tests is a waste of time?" and "Does planning ahead make good things happen?". A high score indicates a more external locus of control.

Self-esteem and scholastic competence. Self-concept is assessed by ratings on the Self-Perception Profile for Children (SPPC) which measures children's selfperception on scales of global self-worth and scholastic competence (Harter 1982). Statements include the following items such as: "some children feel they are very good at their school work but other children worry about whether they can do the school work assigned to them" or "some children are often unhappy with themselves but other children are pretty pleased with themselves". Higher scores represent greater scholastic competence or greater global self-worth.

\section{Covariates}

School Entry Assessment data come from teacheradministered tests, developed by reception teachers in partnership with head teachers, advisors and an educational psychologist, and, while not exactly the same, are remarkably similar to the National Foundation Stage assessments (South Gloucestershire Professional and Curriculum Support Service 1996). The primary purposes of the Entry Assessment were to establish an assessment of strengths and needs for pupils at entry to school, from which to plan, and against which progress can be measured to the end of
KS1. The Entry Assessment is made up of four required areas in language, reading, writing and mathematics, which were administered in the first few weeks of starting Reception (Herrick and Golding 2004).

Strengths and Difficulties at age 6. When the cohort members were 6 , mothers/primary caregivers were asked to complete the Strengths and Difficulties Questionnaire (SDQ), a 25-item behavioural screening questionnaire (Goodman 1997). The SDQ has five sections that cover details of emotional difficulties; conduct problems; hyperactivity or inattention; friendships and peer groups; positive social behaviour.

A number of further control variables were included in the analysis to reduce bias due to omitted variables:

- Household education - combination of both parents' highest level of educational qualifications coded on a scale from 0 to 4: CSE/lower; less than Level 2 academic and vocational qualifications; Olevel/GCSE/Level 2 vocational qualifications; Alevels/Level 3 vocational qualifications; University degree and higher. ${ }^{\text {vii }}$

- Registrar General's classification of Social Class (RGSC) social class

- Experience of financial difficulties

- Mothers' age at the time of the child's birth

- Partner status

- Household tenure

- Birth weight

- Whether (and for how long) the mother breastfed

- Mother-reported locus of control

- Mother-completed Edinburgh Post Natal Depression scale (Cox, Holden and Sagovsky 1987) and Crown Crisp Experiential Index measuring depression, anxiety and somatic symptoms (Crown and Crisp 1979) 
- Mother-child interactions were assessed using the summed responses from the mother/parents to questions about how frequently they sing and read to/with their children, play with them and try to teach them colours, letters and nursery rhymes etc. during the pre-school years. Questions regarding activities outside the home and the number of books and toys in the home during this time were also asked.

\section{Analysis plan}

The focus of this paper is to examine progress and attainment during primary school and understand the balance that exists between change and stability in children's school test scores. To investigate how children progress from Key Stage 1 to 2, as well as what skills predict success at the end of primary school, we adopt two main analytic methods.

\section{How do children progress from Key Stage 1 to Key Stage 2?}

We use transition matrices to investigate Key Stage level and quartile patterns of normative movement and overall stability in progression, also referred to as quartile continuities and discontinuities (see, for example, Blanden and Machin 2007; Feinstein 2004). Transition matrices report the conditional probabilities of being at a certain level or quartile at $\mathrm{KS} 2$, given the relative position in the distribution at KS1. viii They therefore enable a focus on mobility in Key Stage attainment, not only with respect to being 'on-' or 'off-target', but also in terms of who is making the expected levels of progress, and who is exceeding or falling short of the two-level improvement expectations. This information is also used to examine the likelihood of persistence in the top and bottom quartiles by gender and social background.

\section{What Key Stage 1 tests are most important in predicting success at Key Stage 2?}

The second stage of these analyses uses multivariate Ordinary Least Squares (OLS) regression analysis to examine the importance of progress over the KS1 period for attainment at KS2. The interest here lies in estimating the contribution made by each of the key independent variables to attainment in
English and mathematics at KS2. The focus is on the balance between literacy and numeracy-related skills in relation to the different subject domains examined at the end of primary school, and on the particular contribution of attention relative to other developing features of self-regulation. In order to counter problems of omitted variable bias, which is likely to arise if unobserved family or child characteristics are correlated with children's developing academic skills and capabilities and their subsequent educational achievement, we include as many prior measures of relevant child and family characteristics as possible.

\section{Missing data}

The problem of missing data is inherent in the use of longitudinal datasets. Only individuals with complete data for the outcome variables (Key Stage 2) are used in our analysis. We also exclude those who are missing parental education information, in order that we have crucial socio-demographic measures for subsequent analysis, yielding a sample size of $\mathrm{N}=$ 9,994 , approximately $71 \%$ of the original sample of live births. To handle the missing data, we used multiple imputation (MI) techniques (Rubin 1987; Schafer 1997), implemented in STATA. MI does not attempt to estimate each missing value through simulated ones, but rather completes the data several times by imputing multiple random draws of the missing values from a predictive distribution. These multiply imputed datasets are then analysed using standard procedures for complete data, combing the results to obtain overall estimates and standard errors that reflect variability across imputations. This approach assumes that data were missing at random, that is missing, but conditional on other observed characteristics in the data set, although not on the outcome of interest (Schaffer 1997). The advantage of the $\mathrm{MI}$ approach is that these auxiliary variables, while not in the model of interest, can be conditioned on at the imputation stage to improve the efficiency of the imputed data, and so produce more robust and reliable statistical inferences about the population of interest, that better reflect uncertainty due to missing values (see Goldstein 2009, for further discussion of handling attrition and non-response in longitudinal data). 


\section{Results}

In Table 1, we present bivariate correlations between the outcome and key independent variables. For the attainment outcomes, the strengths of these relationships are greatest within the Key Stage assessment period, but the associations over time are also strongly correlated, indicating a high degree of stability across primary school assessment. Correlations are also strongest within subject domains: the KS1 combined measure of literacy is more strongly associated with KS2 English, and KS1 mathematics more with KS2 mathematics. The measures of attention problems are negatively associated - and comparable in size - with the achievement measures at both KS1 and KS2 and, as predicted, more so than any of the other age 8 assessments.

Transition matrices (Table 2) show the average probability, or the likelihood, of a pupil attaining a certain level in Key Stage 2 assessments, given the level they attained at Key Stage 1. Boxes are shaded dark grey to show the (minimum) expected level of progression for each Key Stage level attained over the Key Stage 2 period (lighter grey boxes indicate progress above the two expected levels). For example, within-domain mathematics attainment, $36 \%$ of those achieving the lowest level at
KS1,working towards Level 1, were still below the level of the Key Stage 1 test in their assessments at Key Stage 2. At the top end of the distribution, $73 \%$ of pupils achieving Level 3 or above went on to get at least Level 5 in their mathematics assessment at the end of primary school.

Table 2 also clearly demonstrates that the majority of pupils are achieving the two-level advancement over this Key Stage period, i.e. the considerable stability in mathematics attainment across the two assessments suggested by the correlation matrix: $54 \%$ of pupils gaining Level 1 in KS1 mathematics achieve Level 3 in KS2; $63 \%$ of those on target at Level 2B go on to Level 4 four years later. However, there is also evidence of discontinuity, with pupils both accelerating from and falling behind or off these expected trajectories. For example, the acceleration rate, i.e. those who advance more than the projected two levels (light grey area), from Level 1 at KS1 is $27 \%$, with $4 \%$ of these pupils getting Level $5+$ in KS2. The corresponding fall off rate is $18 \%$, with $7 \%$ progressing to Level 2 and $11 \%$ appearing to have made little or no progress over the KS2 period. The within-domain literacy skill transitions from KS1 reading to KS2 English (Table 3) are comparable.

Table 1. Bivariate correlations between all outcome and key independent variables
(1)
(2)
(3)
(4)
(5)
(6)
(7)

(8)

\begin{tabular}{|c|c|c|c|c|c|c|c|c|c|}
\hline (1) & Key Stage 2 Mathematics & 1 & & & & & & & \\
\hline (2) & Key Stage 2 English & .71 & 1 & & & & & & \\
\hline (3) & Key Stage 1 Mathematics & .66 & .55 & 1 & & & & & \\
\hline (4) & Key Stage 1 English* & .58 & .67 & .71 & 1 & & & & \\
\hline (5) & Age 8 Inattention & -.29 & -.28 & -.31 & -.30 & 1 & & & \\
\hline (6) & Age 8 Locus of Control & -.25 & -.25 & -.24 & -.24 & .12 & 1 & & \\
\hline (7) & Age 8 Scholastic Competence & .22 & .20 & .23 & .23 & -.11 & -.21 & 1 & \\
\hline (8) & Age 8 Self Esteem & .09 & 11 & .09 & .11 & -.08 & -.16 & .42 & 1 \\
\hline
\end{tabular}

Table notes. All significant at $5 \%$

* Key Stage 1 English is the first factor solution of the reading, writing and spelling assessments 
Table 2. Transition matrix: Key Stage 1 mathematics to Key Stage 2 mathematics KS2 Mathematics

\begin{tabular}{lc|c|c|c|c}
\hline KS1: Mathematics & Below Lev 2 & Lev 2 & Lev 3 & Lev 4 & Lev 5+ \\
\hline Working towards L1 & .36 & .11 & .39 & .10 & .03 \\
Level 1 & .11 & .07 & .54 & .23 & .04 \\
Level 2C & .01 & .02 & .39 & .50 & .08 \\
Level 2B & .00 & .00 & .16 & .63 & .21 \\
Level 2A & .00 & .00 & .05 & .55 & .40 \\
Level 3+ & .00 & .00 & .02 & .25 & .73 \\
\hline Total & .01 & .01 & .16 & .45 & .36 \\
\hline
\end{tabular}

Table notes. $\mathrm{N}=9,444$

Table 3. Transition matrix: Key Stage 1 mathematics to Key Stage 2 English KS2 English

\begin{tabular}{|c|c|c|c|c|c|}
\hline KS1: Reading & Below Lev 2 & Lev 2 & Lev 3 & Lev 4 & Lev 5 \\
\hline $\begin{array}{l}\text { Working towards } \\
\text { L1 }\end{array}$ & .30 & .12 & .41 & .15 & .01 \\
\hline Level 1 & .09 & .07 & .47 & .34 & .04 \\
\hline Level 2C & .01 & .02 & .32 & .56 & .09 \\
\hline Level 2B & .00 & .00 & .12 & .71 & .17 \\
\hline Level 2A & .00 & .00 & .05 & .66 & .29 \\
\hline Level 3+ & .00 & .00 & .01 & .35 & .63 \\
\hline Total & .01 & .01 & .14 & .51 & .33 \\
\hline
\end{tabular}

Table notes. $N=9,444$ 


\section{The relative importance of developing capabilities during middle childhood}

The findings so far highlight both change and continuity in the development of literacy and numeracy skills throughout the primary school years as measured by Key Stage assessments. The second stage of this analysis examines what skills predict success at KS2 and uses regression analysis to estimate the importance of changes measured in literacy and numeracy achievement, attentional skills, and related features of self-regulation during middle childhood for predicting success at KS2 in English and mathematics.

Tables 4 and 5 show the regressions of the KS2 English and mathematics, respectively, on the KS1 assessments in mathematics and literacy, and the age 8 clinic assessments of self-regulation and individual adjustment. All models control for age in weeks and gender. Model 1 in each table, shows the bivariate association between each on the key independent variables and the outcome of interest. Model 2 adds both KS1 measures into the model simultaneously, and model 3 shows the associations with each outcome when only the age 8 clinic assessments are included. Model 4 gives the associations when all the key independent variables are included. The next model, Model 5, adds the controls for child and family background characteristics. This is our preferred model of the "effects" of early skills and capabilities on KS2 attainment: given that when we control for prior measures of mathematics and English attainment and earlier attention and self-regulatory skills, the coefficients on the key independent variables of interest carry a change interpretation. While this change model is considerably more robust to omitted variable bias than is a model using static measures at a given age, we remain cautious in making strong claims of causality. ${ }^{\text {ix }}$ Finally, Model 6 reports the conditional estimates for the five age 8 clinic assessments only, i.e. it excludes the KS1 and Entry Assessment achievement measures, in order to better assess the contributions that these broader capabilities and self-regulatory skills make to later academic attainment, that could have been diluted through their inclusion; while attentional skills have been shown to relate to academic achievement independent of prior cognitive performance, it is likely that aspects of self-regulatory capabilities are picked up within the assessment of academic skills. Coefficients are shown in the adjusted metric of KS2 levels summarised above, such that each unit increase in the KS1 test or age 8 clinic assessment, equates to a corresponding increase in the KS2 level. 
Table 4. Coefficients and standard errors from regression models of Key Stage 2 mathematics on Key Stage 1 assessments and age 8 clinic measures

Key Stage 2 Mathematics

\begin{tabular}{|c|c|c|c|c|c|c|c|c|c|c|c|c|}
\hline Model: & $(1)$ & & $(2)$ & & (3) & & (4) & & (5) & & (6) & \\
\hline \multicolumn{13}{|l|}{ Key Stage 1 assessments } \\
\hline Mathematics & $\begin{array}{l}.56 \\
(.01)\end{array}$ & $* * *$ & $\begin{array}{l}.40 \\
(.01)\end{array}$ & $* * *$ & & & $\begin{array}{l}.38 \\
(.01)\end{array}$ & $* * *$ & $\begin{array}{l}.34 \\
(.01)\end{array}$ & $* * *$ & & \\
\hline English & $\begin{array}{l}.50 \\
(.01)\end{array}$ & $* * *$ & $\begin{array}{l}.23 \\
(.01)\end{array}$ & $* * *$ & & & $\begin{array}{l}.20 \\
(.01)\end{array}$ & $* * *$ & $\begin{array}{l}.15 \\
(.01)\end{array}$ & $* * *$ & & \\
\hline \multicolumn{13}{|l|}{ Clinic assessments at age 8} \\
\hline Inattention & $\begin{array}{l}-.25 \\
(.01)\end{array}$ & $* * *$ & & & $\begin{array}{l}-.23 \\
(.01)\end{array}$ & $* * *$ & $\begin{array}{l}-.06 \\
(.01)\end{array}$ & $* * *$ & $\begin{array}{l}-.06 \\
(.01)\end{array}$ & $* * *$ & $\begin{array}{l}-.18 \\
(.01)\end{array}$ & $* * *$ \\
\hline Locus of control & $\begin{array}{l}-.22 \\
(.01)\end{array}$ & $* * *$ & & & $\begin{array}{l}-.17 \\
(.01)\end{array}$ & $* * *$ & $\begin{array}{l}-.06 \\
(.01)\end{array}$ & $* * *$ & $\begin{array}{l}-.03 \\
(.01)\end{array}$ & $* * *$ & $\begin{array}{l}-.09 \\
(.01)\end{array}$ & $* * *$ \\
\hline Scholastic competence & $\begin{array}{l}.18 \\
(.01)\end{array}$ & $* * *$ & & & $\begin{array}{l}.13 \\
(.01)\end{array}$ & $* * *$ & $\begin{array}{l}.04 \\
(.01)\end{array}$ & $* * *$ & $\begin{array}{l}.04 \\
(.01)\end{array}$ & $* * *$ & $\begin{array}{l}.10 \\
(.01)\end{array}$ & $* * *$ \\
\hline Self esteem & $\begin{array}{l}.07 \\
(.01)\end{array}$ & $* * *$ & & & $\begin{array}{l}-.02 \\
(.01)\end{array}$ & $*$ & $\begin{array}{l}-.01 \\
(.01)\end{array}$ & & $\begin{array}{l}-.01 \\
(.01)\end{array}$ & & $\begin{array}{l}-.03 \\
(.01)\end{array}$ & $* *$ \\
\hline \multicolumn{13}{|l|}{ Entry assessments } \\
\hline Mathematics & & & & & & & & & $\begin{array}{l}.07 \\
(.01)\end{array}$ & $* * *$ & & \\
\hline English & & & & & & & & & $\begin{array}{l}.03 \\
(.01)\end{array}$ & $* *$ & & \\
\hline \multicolumn{13}{|l|}{ Strengths and Difficulties at age 6} \\
\hline Inattentive/Hyperactive behaviour & & & & & & & & & $\begin{array}{l}-.04 \\
(.01)\end{array}$ & $* * *$ & $\begin{array}{l}-.12 \\
(.01)\end{array}$ & $* * *$ \\
\hline Conduct Disorder & & & & & & & & & $\begin{array}{l}-.02 \\
(.01)\end{array}$ & & $\begin{array}{l}-.03 \\
(.01)\end{array}$ & $*$ \\
\hline Prosocial behaviour & & & & & & & & & $\begin{array}{l}-.02 \\
(.01)\end{array}$ & $*$ & $\begin{array}{l}-.03 \\
(.01)\end{array}$ & $* *$ \\
\hline Emotional problems & & & & & & & & & $\begin{array}{l}-.01 \\
(.01)\end{array}$ & & $\begin{array}{l}-.01 \\
(.01)\end{array}$ & \\
\hline Peer problems & & & & & & & & & $\begin{array}{l}.00 \\
(.01)\end{array}$ & & $\begin{array}{l}-.01 \\
(.01)\end{array}$ & \\
\hline Girl & & & $\begin{array}{l}-.17 \\
(.01) \\
\end{array}$ & $* * *$ & $\begin{array}{l}-.12 \\
(.02) \\
\end{array}$ & $* * *$ & $\begin{array}{l}-.17 \\
(.01) \\
\end{array}$ & $* * *$ & $\begin{array}{l}-.17 \\
(.01) \\
\end{array}$ & $* * *$ & $\begin{array}{l}-.13 \\
(.02) \\
\end{array}$ & $* * *$ \\
\hline Controls & & & & & & & & & $x$ & & $x$ & \\
\hline Observations & 9994 & & 9994 & & 9994 & & 9994 & & 9994 & & 9994 & \\
\hline R-squared & - & & .47 & & .19 & & .48 & & .51 & & .29 & \\
\hline
\end{tabular}

Table notes. $* * * \mathrm{p}<.001, * * \mathrm{p}<.01, * \mathrm{p}<.05$

All independent variables shown are standardised $(M=0$, Std. Dev. $=1)$. Robust standard errors in brackets.

Control variables include: parents' education, parents' socioeconomic group, housing tenure, experience of financial difficulties, mothers' age at birth of child, birth weight, maternal general and postnatal depression, mothers' social networks, mother-child interaction, educational behaviours and number of books in the home. 
Table 5. Coefficients and standard errors from regression models of KS2 English on KS1 assessments and age 8 clinic measures

\section{Key Stage 2 English}

Model: (1) (2)

\begin{tabular}{|c|c|c|c|c|c|c|c|c|c|c|c|c|}
\hline \multirow{3}{*}{$\begin{array}{l}\text { Key Stage } 1 \text { assessments } \\
\text { Mathematics }\end{array}$} & \multicolumn{2}{|c|}{ (1) } & \multicolumn{2}{|c|}{ (2) } & \multicolumn{2}{|c|}{ (3) } & \multicolumn{2}{|c|}{ (4) } & \multicolumn{2}{|c|}{ (5) } & \multicolumn{2}{|c|}{ (6) } \\
\hline & .41 & $* * *$ & .14 & $* * *$ & & & .11 & $* * *$ & .08 & $* * *$ & & \\
\hline & $(.01)$ & & $(.01)$ & & & & $(.01)$ & & $(.01)$ & & & \\
\hline English & .52 & $* * *$ & .41 & $* * *$ & & & .39 & $* * *$ & .33 & $* * *$ & & \\
\hline & $(.01)$ & & $(.01)$ & & & & $(.01)$ & & $(.01)$ & & & \\
\hline \multicolumn{13}{|l|}{ Clinic assessments at age 8} \\
\hline \multirow[t]{2}{*}{ Inattention } & -.22 & $* * *$ & & & -.18 & $* * *$ & -.04 & $* * *$ & -.05 & $* * *$ & -.14 & $* * *$ \\
\hline & $(.01)$ & & & & $(.01)$ & & $(.01)$ & & $(.01)$ & & (.01) & \\
\hline \multirow[t]{2}{*}{ Locus of control } & -.19 & $* * *$ & & & -.15 & $* * *$ & -.06 & $* * *$ & -.04 & $* * *$ & -.08 & $* * *$ \\
\hline & $(.01)$ & & & & $(.01)$ & & $(.01)$ & & $(.01)$ & & $(.01)$ & \\
\hline \multirow[t]{2}{*}{ Scholastic competence } & .14 & $* * *$ & & & .08 & $* * *$ & .01 & & .01 & & .06 & $* * *$ \\
\hline & $(.01)$ & & & & $(.01)$ & & $(.01)$ & & $(.01)$ & & $(.01)$ & \\
\hline \multirow[t]{2}{*}{ Self esteem } & .08 & $* * *$ & & & .00 & & .01 & & .01 & & .00 & \\
\hline & (.01) & & & & $(.01)$ & & $(.01)$ & & $(.01)$ & & $(.01)$ & \\
\hline \multicolumn{13}{|l|}{ Entry assessments } \\
\hline \multirow[t]{2}{*}{ Mathematics } & & & & & & & & & .03 & $* * *$ & & \\
\hline & & & & & & & & & $(.01)$ & & & \\
\hline \multirow[t]{2}{*}{ English } & & & & & & & & & .06 & $* * *$ & & \\
\hline & & & & & & & & & $(.01)$ & & & \\
\hline \multicolumn{13}{|l|}{ Strengths and Difficulties at age 6} \\
\hline \multirow[t]{2}{*}{ Inattentive/Hyperactive behaviour } & & & & & & & & & -.04 & $* * *$ & -.11 & $* * *$ \\
\hline & & & & & & & & & $(.01)$ & & $(.01)$ & \\
\hline \multirow[t]{2}{*}{ Conduct Disorder } & & & & & & & & & -.01 & & -.03 & $* *$ \\
\hline & & & & & & & & & $(.01)$ & & $(.01)$ & \\
\hline \multirow[t]{2}{*}{ Prosocial behaviour } & & & & & & & & & -.01 & & -.02 & $* *$ \\
\hline & & & & & & & & & $(.01)$ & & $(.01)$ & \\
\hline \multirow[t]{2}{*}{ Emotional problems } & & & & & & & & & .00 & & .00 & \\
\hline & & & & & & & & & $(.01)$ & & $(.01)$ & \\
\hline \multirow[t]{2}{*}{ Peer problems } & & & & & & & & & -.01 & & -.01 & \\
\hline & & & & & & & & & $(.01)$ & & $(.01)$ & \\
\hline \multirow[t]{2}{*}{ Girl } & & & .12 & $* * *$ & .23 & $* * *$ & .12 & $* * *$ & .11 & $* * *$ & .21 & $* * *$ \\
\hline & & & $(.01)$ & & $(.01)$ & & $(.01)$ & & $(.01)$ & & $(.01)$ & \\
\hline Controls & & & & & & & & & $\mathrm{x}$ & & $\mathrm{X}$ & \\
\hline Observations & 9994 & & 9994 & & 9994 & & 9994 & & 9994 & & 9994 & \\
\hline R-squared & - & & .46 & & .20 & & .48 & & .51 & & .32 & \\
\hline
\end{tabular}

Table notes. ${ }^{* * *} p<.001, * * p<.01, * p<.05$

All independent variables shown are standardised $(M=0$, Std. Dev. $=1)$. Robust standard errors in brackets.

Control variables include: parents' education, parents' socioeconomic group, housing tenure, experience of financial difficulties, mothers' age at birth of child, birth weight, maternal general and postnatal depression, mothers' social networks, mother-child interaction, educational behaviours and number of books in the home. 
Beginning with the bivariate relationships shown in Model 1, all the coefficients are statistically significant in the expected direction. ${ }^{\times}$As expected, the KS1 coefficients are largest, followed by inattention. Taken together, the results support the claim regarding the simple predictiveness of a broad set of skills for subsequent academic achievement.

Models 2 and 3 estimate models when both KS1 achievement measures and, respectively, all five age 8 clinic assessments are included. Model 2 highlights the domain-specific continuity in Key Stage assessments, whereby earlier mathematics is more predictive of later mathematics than later English score and vice versa. The bivariate relationships are reduced for both KS1 measures when they are included simultaneously, but it is interesting to note that the overall measure of KS1 literacy is more predictive of later mathematics than earlier mathematics is for subsequent English, reflecting the fundamental need to be able to read and write to do well in mathematics. For both KS2 outcomes considered, just under half of the variance is explained by the KS1 tests alone, $47 \%$ for mathematics and $46 \%$ for English. In Model 3, of the clinic assessments, age 8 inattention remains the most important predictor of both KS2 English and mathematics, followed by locus of control and scholastic competence. Approximately $20 \%$ of the variance in the KS2 outcomes is explained by these four variables. In Model 4, all the key independent variables are included in the estimation. The associations of both KS1 measures are reduced further, but those for attention and individual adjustment drop considerably - often by three quarters and for some, to the point of statistical insignificance. Thus, it appears that important portions of the simple associations between achievement at the end of primary school and middle childhood capabilities, are the result of their mutual correlation.

Estimates presented in Model 5 are derived from our preferred model of the "effects" of early skills and capabilities on KS2 attainment, which adjust the bivariate associations for prior attainment and selfregulation and for family and child characteristics. These results again show a very strong pattern of stability within the Key Stage assessments, with the KS1 tests being substantial predictors of both subsequent KS2 English and mathematics achievement, conditional on earlier levels of attainment, attentional skills and related features of self-regulation and individual adjustment, as well as other comprehensive measures of the child and family background characteristics. Moreover, the size of these estimates on the key independent variables hardly change when these additional control sets are introduced, with both KS1 predictors, attentional skills, locus of control and, for mathematics, scholastic competence remaining highly statistically significant. The results also show that girls do better in KS2 English, but boys do better in mathematics.

As noted above, the strength of these relationships is strongest within subject areas, reflecting strong within-domain continuity, with attentional skills and locus of control being roughly equal in size for both KS2 outcomes. For example, the conditional estimates show that each standard deviation increase in mathematics achievement over the KS1 period, results in an additional .34 of a level in KS2 mathematics - this equates to approximately 8 months' progress. There is also evidence that development in literacy and numeracy skills over the KS1 period is important for later cross-domain outcomes - particularly regarding prior literacy skills. For example, a one unit increase in KS1 literacy, results on average, in an increase of .15 of a level in KS2 mathematics - roughly 4 months' progress. An increase in one level in KS1 mathematics raises KS2 English attainment by .08 of a level, or 2 months' learning.

The final model, Model 6, includes earlier controls for individual adjustment and our comprehensive control set, but not the attainment measures, in order to highlight the relative magnitude of the attention and related self-regulatory skills measured at age 8 , which may be diminished owing to the strong degree of continuity in the Key Stage assessments. For both KS2 English and mathematics, the measure of inattention is at least twice the size of the other predictors, and is the coefficient most reduced through the inclusion of the attainment measures, suggesting, in line with the correlations reported above and literature reviewed, that attentional skills are a particularly salient element of academic achievement and performance. 


\section{Discussion}

\section{Stability and change in primary school attainment}

In line with other developmental research, the results presented here emphasise a high degree of continuity in academic attainment. Examination of the correlations, transition matrices, and regression models all indicate a great deal of stability in attainment in the primary school National Curriculum tests. The majority of pupils are advancing the expected two levels over the KS2 period, more so at the top end of the KS1 distribution, and at an average level, progression between Key Stage 1 and 2 appears remarkably stable. However, detailed consideration of the transition matrices, suggests that there is also some movement away from this "normative" pattern in pupils' progression during primary school. That is, although the majority of pupils are advancing the expected two levels over the KS2 period, there are others who buck this trend, both accelerating from and falling off these average 'target' trajectories. In future analysis, we hope to concentrate in more detail on these "off-diagonal" individuals, to investigate what predicts this departure, and how it relates to subsequent performance, as well as the extent to which it might result from mis-classification.

These findings support earlier work by Feinstein (2004) and Schoon (2006) which report mobility in the relative position of pupils' attainment in primary and secondary school for the 1958 National Child Development Study (NCDS) and 1970 British Cohort Study (BCS). Using similar quartile-based transition matrix analysis, Feinstein (2004) shows that, in the NCDS, 35 per cent of those in the bottom quartile of general academic ability at age 7, have 'escaped', i.e. are no longer in, the bottom quartile by age 11 . Conversely the probability of 'dropping out' of the top quartile between 7 and 11 is 44 per cent. For the 1970 cohort, the escape rate from the bottom quartile between 5 and 10 years was 46 per cent and the drop out rate from the top quartile was 50 per cent. The results presented in this paper show a similar likelihood of escaping the bottom quartile, with $37 \%$ per cent of pupils moving out of the bottom quartile by $\mathrm{KS} 2$ for mathematics and a higher probability, nearly $43 \%$, of exiting the top quartile. ${ }^{\mathrm{xi}}$

\section{Effects within and between subjects}

In line with other research (for example, Melhuish et al 2006), these results also demonstrate the strength of within-subject influences of pupils' literacy and numeracy skills. As children move from early childhood into middle childhood and gain increasing experiences of formal education, they become more adept at acquiring new information and using this to develop more mature modes of thought. Consequently, specific literacy and numeracy skills become more advanced as children move through primary school and thus show greater within-domain continuity over time. Feinstein (1998) also finds evidence of cross-domain skills in the early years, which lessen with experience of formal schooling. The relative contribution of attentional skills, however, is roughly the same for both KS2 mathematics and English, reflecting the ways in which attentional resources underpin educational success, broadly defined.

Further research is required to establish the longitudinal stability and validity of the Key Stage curriculum assessments, and whether the high degree of stability observed in these assessments signals genuine continuity in development and resulting attainment, or is merely a product of common assessment.

\section{The relative importance of attentional skills}

Like those of Duncan et al (2007) and Breslau et al $(2009,2010)$, the results presented here show evidence of the important role of attention skills in predicting later achievement. The measure of inattention at age 8 carries particularly strong negative predictions for both measures of achievement at the end of primary school. Moreover, when the KS1 and entry assessment measures are excluded from the estimation (Model 6), the coefficients for inattention increase considerably, by approximately three times, indicating that measures of school performance also measure aspects of attention-related skills. This finding is consistent with other research, highlighting that attentional skills operate independently of cognitive ability (Alexander et al 1993; Duncan et al 2007; McClelland et al 2000; Yen et al 2004). These findings thus suggest that, to the extent that pupils' poor attentional skills can be 
improved in the early school years, their potential for academic achievement might be improved as well.

The earlier SDQ measure of inattentive/ hyperactive behaviour also shows a strong negative association with achievement at the end of primary school, over and above the age 8 TEACh assessment of attentional skills. As noted above, attention is not a unitary brain process, and several authors note the difficulties faced by psychometrists in capturing such a construct with precision (Manly et al 2001). That both the behavioural manifestation of attention problems reflected in the maternal report of the $S D Q$, ${ }^{x i}$ and the individual performance-based measures of attentional control, independently predict academic achievement, reflects such complexity.

Future research would thus benefit from studies which illuminate the natural course of development in both attention-related skills, related behavioural problems and the interactions between them during primary school, examining whether there is variation by gender, social background or at different skill levels. For example, recent research from the US by Diprete and Jennings (2009) finds gender differences in the acquisition of attention and related selfregulation skills, and shows that it is this difference that explains a considerable proportion of the gender gap in academic outcomes during early schooling. Their results indicate that boys get roughly the same academic return to social and behavioural skills as their female peers, but girls retain an advantage both because they start school with more advanced selfregulatory skills and because their skill advantage grows over time. Breslau et al (2010) also suggest that changes in self-regulation skills occurring during middle childhood, may be an important mechanism for the observed declines in academic achievement of some children during this period.

\section{The role of the wider developmental context}

The results of the multiple regression analyses indicate that the substantial continuity observed in the Key Stage assessments is fairly independent of wider developmental contexts. The four KS1 scores alone, account for $47 \%$ and $46 \%$ of the variance in KS2 mathematics and English assessments respectively, and when comprehensive controls for family background, parenting, and earlier child-level skills and capabilities are entered into the regression estimation, the proportion of variance explained does not substantially increase. That is not to say that features of the child and their family background do not matter for attainment in primary school, but that family background factors might have already exerted their considerable influence in the pre-school years (Feinstein 2003; Schoon 2006; Schoon et al (this issue). Furthermore, research by Sacker and colleagues (2002) demonstrates the importance of the timing of contextual influences on children's development, and suggests that family influences, such as parental involvement, become less important and school composition more so, in relation to educational achievement and psychosocial adjustment, as children move from middle to late childhood. An important avenue for research to pursue in the future, would be to similarly decompose the differential impact of changing contextual influences on attentional skills over time.

The analyses presented in this study show that while the average picture in children's academic achievement during primary school is one of stability, in line with the literature reviewed in the introduction, there is considerable mobility in attainment. Academic achievement is far from set in stone, yet neither is it a function of cognitive competencies alone, but a multi-dimensional construct involving skills and support structures that enable pupils to regulate their own learning. The results presented here thus highlight the need to understand better the balances of stability and change, continuity and discontinuity, alongside more holistic approaches and definitions of educational success, in order that all children are to be able to make the most of their learning opportunities and make good progress. Recognition and appreciation of these shifts and fluctuations are central to a focus on personalised learning, and are fundamental to closing the attainment gaps. Failure to appreciate this malleability is likely to lead to over-determining the meaning of these tests, and the result is likely to be that under-achievement becomes entrenched. 


\section{Acknowledgements}

The analysis and writing of this paper were supported by grants from the UK Economic and Social Research Council (ESRC): RES-594-28-0001 and RES-060-23-0011. Those who carried out the original collection of the data bear no responsibility for its further analysis and interpretation.

We are grateful to all the mothers who took part in the study and to the midwives for their cooperation and help in recruitment. The whole ALSPAC Study Team comprises interviewers, computer technicians, laboratory technicians, clerical workers, research scientists, volunteers and managers who continue to make the study possible. The ALSPAC study has been supported by funding from the Medical Research Council, the Wellcome Trust, UK government departments, medical charities and others, and is part of the World Health Organisationinitiated European Longitudinal Study of Pregnancy and Childhood.

\section{References}

Alexander KL, Entwisle DR and Dauber SL. (1993) First grade classroom behavior: its short- and long-term consequences for school performance. Child Development, 64, 801-814.

Barriga AQ, Doran JW, Newell SB, Morrison EM, Barbetti V and Robbins BD. (2002) Relationships between problem behaviors and academic achievement in adolescents: the unique role of attention problems. Journal of Emotional and Behavioral Disorders, 10(4), 233-240.

Blackwell LS, Trzesniewski K and Dweck CS. (2007) Implicit theories of intelligence predict achievement across an adolescent transition: a longitudinal study and an intervention. Child Development, 78(1), 246-263.

Blanden J and Machin S. (2007) Recent changes in intergenerational mobility in Britain. The Sutton Trust, London.

Breslau J, Breslau N, Bohnert K, Lucia VC and Schweitzer J. (2009) The impact of early behavior disturbances on academic achievement in high school. Pediatrics, 123(6), 1472-1476.

Breslau N, Breslau J, Peterson E, Miller E, Lucia VC, Bohnert K et al. (2010) Change in teachers' ratings of attention problems and subsequent change in academic achievement: a prospective analysis. Psychological Medicine, 40, 159-166.

Chan RCK, Lai MK and Robertson IH. (2006) Latent structure of the Test of Everyday Attention in a non-clinical Chinese sample. Archives of Clinical Neuropsychology, 21, 477-485.

Collins WA. (1984) Development during middle childhood. National Academy Press,

Washington, DC.

Cox JL, Holden JM and Sagovsky R. (1987) Edinburgh Postnatal Depression Scale (EPDS). Department of Psychiatry, University of Edinburgh.

Crown S and Crisp AH. (1979) Manual of the Crown-Crisp Experiential Index. Hodder and Stoughton, London.

Deci EL and Ryan RM. (1987) The support of autonomy and the control of behavior. Journal of Personality and Social Psychology, 53(6), 1024-1037.

Department for Education and Skills (2003). Statistics First Release Bulletin SFR 33/2003: http://www.dcsf.gov.uk/rsgateway/DB/SFR/s000433/sfr33-2003.pdf.

Department for Education and Skills. (2006) Making Good Progress: How can we help every pupil to make good progress at school? Consultation document.

Diamond A, Barnett WS, Thomas J and Munroe S. (2007) Preschool program improves cognitive control. Science, $318,1387-1388$

Diprete TA and Jennings JL. (2009) Social/Behavioral skills and the gender gap in early educational achievement (CPRC Working Paper No. 09-08). Columbia Population Research Center, New York.

Duncan G J, Dowsett C J, Claessens A, Magnuson K, Huston AC, Klebanov P, Pagani LS, Feinstein L, Engel M, Brooks-Gunn J, Sexton H, Duckworth K and Japel C. (2007). School Readiness and Later Achievement. Developmental Psychology, 43(6), 1428-1446.

Feinstein L. (1998) Pre-School Educational Inequality: British Children in the 1970 Cohort (Discussion Paper 404). Centre for Economic Performance, London.

Feinstein L. (2004) Mobility in pupils' cognitive attainment during school life. Oxford Review of Economic Policy, 20(2), 213-229.

Feinstein L and Bynner J. (2004) The importance of cognitive development in middle childhood for adulthood socioeconomic status, mental health, and problem behaviour. Child Development, 75(5), 1329-1339.

Golding J, Pembrey M, Jones R and the ALSPAC Study Team. (2001) The Avon Longitudinal Study of Parents and Children. I. Study methodology. Paediatric Perinatal Epidemiology, 15, 74-87. 
Goldstein H. (2009) Handling attrition and non-response in longitudinal data. Longitudinal and Life Course Studies, 1(1), 63-72.

Goodman R. (1997) The Strengths and Difficulties Questionnaire: a Research Note. Journal of Child Psychology and Psychiatry, 38, 581-586.

Hallam S, Rhamie J and Shaw J. (2006) Evaluation of the Primary Behaviour and Attendance Pilot (RR 717). Department for Education and Skills, London.

Harter S. (1982) The perceived competence scale for children. Child Development, 53, 87-97.

Heckman JJ and Rubinstein Y. (2001) The importance of noncognitive skills: lessons from the GED Testing Program. The American Economic Review, 91(2), 145-149.

Heckman JJ, Stixrud J and Urzua S. (2006) The effects of cognitive and non-cognitive abilities on labor market outcomes and social behavior. Journal of Labor Economics, 24, 411-482.

Hiebert J and Wearne D. (1996) Instruction, understanding, and skill in multidigit addition and subtraction. Cognition and Instruction, 14, 251-283.

Huang-Pollock CL, Carr TH and Nigg JT. (2002) Development of selective attention: perceptual load influences early versus late attentional selection in children and adults. Developmental Psychology, 38, 363-375.

Huston AC and Ripke MN. (2006) Developmental contexts in middle childhood. New York: Cambridge University Press.

Keating DP. (2004) Cognitive and brain development. In RJ Lerner and LD Steinberg eds. Handbook of adolescent psychology. Pp 45-84, $2^{\text {nd }}$ vol, Wiley \& Sons, New York.

Kowleski-Jones L and Duncan GJ. (1999) The Structure of Achievement and Behavior across Middle Childhood. Child Development, 70(4), 930-943.

Lefcourt H. (1982) Locus of control: current trends in theory and research. (2nd ed). Lawrence Erlbaum, Hillsdale, NJ.

Leppänen U, Niemi P, Aunola K and Nurmi J. (2006) Development of reading and spelling Finnish from preschool to Grade 1 and Grade 2. Scientific studies of reading, 10(1), 3-30.

Levačić R, Jenkin A, Vignoles A, Steele F and Allen R. (2005) Estimating the relationship between school resources and pupil attainment at Key Stage 3. (Research Report No.679). DfES, London.

Manly T, Anderson V, Nimmo-Smith I, Turner A, Watson P and Robertson IH. (2001) The differential assessment of children's attention: The Test of Everyday Attention for Children (TEA-Ch), normative sample and ADHD performance. Journal of Child Psychology and Psychiatry, 42(8), 1065-1081.

McCall RB, Appelbaum MI and Hogarty PS. (1973) Developmental changes in mental performance. Monographs of the Society for Research in Child Development, 38 (3, Serial No. 150).

McClelland M, Morrison FJ and Holmes DL. (2000) Children at risk for early academic problems: the role of learning-related social skills. Early Childhood Research Quarterly, 15, 307-329.

Melhuish E, Romaniuk H, Sammons P, Sylva K, Siraj-Blatchford I and Taggart B. (2006) The effectiveness of primary schools in England in Key Stage 2 for 2002, 2003 and 2004. DfES / Institute of Education, London.

Nowicki S and Duke MP. (1974) A preschool and primary internal-external control scale. Developmental Psychology, 10, 874-881.

Posner MI and Petersen SE. (1990) The attention system of the human brain. Annual Review of Neuroscience, 13, 25-42.

Pungello EP, Kupersmidt JB, Burchinal MR and Patterson CJ. (1996) Environmental risk factors and children's achievement from middle childhood to early adolescence. Developmental Psychology, 32(4), 755-767.

Raver CC, Smith-Donald R, Hayes T and Jones SM. (2005) Self-regulation across differing risk and sociocultural contexts: preliminary findings from the Chicago School Readiness Project. Paper presented at the biennial meeting of the Society for Research in Child Development, Atlanta, GA.

Rimm-Kaufmann SE, Fan X, Chiu Y and You W. (2007) The contribution of the responsive classroom approach on children's academic achievement: results from a three year longitudinal study. Journal of School Psychology, 45, 401-421.

Robertson IH. Ward T, Ridgeway V and Nimmo-Smith I. (1996) The structure of normal human attention: the Test of Everyday Attention. Journal of the International Neuropsychological Society, 2, 525-534.

Rubin DB. (1987) Multiple Imputation for Nonresponse in Surveys. Wiley and Sons, New York.

Sacker A, Schoon I and Bartley M. (2002) Social inequality in educational achievement and psychosocial adjustment throughout childhood: magnitude and mechanisms. Social Science and Medicine, 55, 863880.

Scarborough HS. (2001) Connecting early language and literacy to later reading (dis)abilities: evidence, theory, and practice. In SB Neuman and DK Dickinson. eds. Handbook of early literacy research. The Guilford Press, New York. 
Schafer JL. (1997) Analysis of incomplete multivariate data. Chapman and Hall, London.

Schoon I. (2006) Risk and resilience: adaptations in changing times. Cambridge University Press, Cambridge.

Schoon I, Hope S, Ross A and Duckworth K. (2010) Family hardship and school readiness: a study of mediating processes in the first three years of life. Longitudinal and Life Course Studies 1, 209-222.

Siegler RS and Alibali MW. (2004) Children's thinking. Prentice Hall, Upper Saddle River, NJ.

South Gloucestershire Professional and Curriculum Support Service. (1996) Entry Assessment in South Gloucestershire. Woodspring Educational Resource Centre, Weston-super-Mare.

Storch SA and Whitehurst GJ. (2002) Oral language and code-related precursors to reading: evidence from a longitudinal structural model. Developmental Psychology, 38, 934-947.

Wilson RS. (1983) The Louisville twin study: developmental synchronies in behaviour. Child Development, 54, 298-316.

Yen C, Konold TR and McDermott PA. (2004) Does learning behavior augment cognitive ability as an indicator of academic achievement? Journal of School Psychology, 42, 157-169.

Zins JE, Bloodworth MR, Weissberg RP and Walberg HJ. (2004) The scientific base linking social and emotional learning to school success. In JE Zins, RP Weissberg, MC Wang and HJ Walberg. eds. Building academic success on social and emotional learning: what does the research say? Pp 3-22. Teachers College Press, New York.

\section{Endnotes}

${ }^{i}$ Key Stage 1 is the term for the two years of schooling in maintained schools in England and Wales normally known as Year 1 and Year 2, when pupils are aged between 5 and 7.

ii An area around Bristol in the South West of England

iii Mothers who were resident in the area but left shortly after enrolment were omitted from further follow-up. However, those who had completed the questionnaire scheduled for the third trimester of pregnancy before leaving the study area have been kept in the study, even if they had not delivered at the time of moving.

iv The National Curriculum Key Stages are built on 10 levels which cover the range $5-16$ years and are arranged so that, on average, pupils are expected to progress one level every two years. A coefficient of 0.5 therefore equates to approximately one year's progress, a coefficient of 0.25 , approximately six months' progress and so on.

${ }^{v}$ Level $4+$ is assessed by means of KS2 materials. However, there were so few children achieving Level $4+(\mathrm{N}=10)$ that it has been combined with Level 3.

vi "Disapplied" is a formal DCSF term defined as the very small number of pupils who are not able to take part in some or all of the assessment arrangements, even allowing for the full range of special arrangements that can be made. Usually this only happens if all or part of the National Curriculum is not suitable for a pupil because he or she has certain special educational needs. Source: http://www.dcsf.gov.uk/performancetables/primary_01/glossary.shtml

vii Where father/partner's education is not available, we use mother's education.

viii Information on school level clustering was not available at the time of analysis to carry out multilevel modelling so as to examine any peer group effects here.

${ }^{i x}$ It should be noted, however, that from a developmental perspective, there is not absolute continuity of meaning and measurement across these ages as cognitive ability and behaviour are still being acquired. Hence, it is inevitable that error and instability in measurement remain and so reduce the extent to which a change interpretation in a strict econometric sense is appropriate.

${ }^{x}$ Higher scores in locus of control assessments indicate individuals have a more externalised sense of perceived control in their lives where fate and luck are more in control.

${ }^{x i}$ Owing to space limitations the quartile transition matrices for these data are not shown. Tables are available from the authors on request.

xii The SDQ sub-scale is made up of five items covering parental reports of restless, overactive behaviour; constant fidgeting; easily distracted; thinking before acting; and having a good attention span. 
